\section{RESEARCH REPORTS}

Clinical

T. Pinho', P. Maciel², C. Lemos ${ }^{3,4}$, and A. Sousa ${ }^{3,4^{*}}$

${ }^{1}$ Centro de Investigação Ciências da Saúde (CICS), Instituto Superior de Ciências da Saúde-Norte/CESPU, Portugal; ${ }^{2}$ Life and Health Sciences Research Institute (ICVS), School of Health Sciences, University of Minho, Braga, Portugal; ${ }^{3}$ Department of Population Studies, ICBAS, University of Porto, Largo Abel Salazar, 2, 4099003 Porto, Portugal; and ${ }^{4}$ UnIGENe, Institute for Molecular and Cell Biology (IBMC), Porto, Portugal; *corresponding author, absousa@icbas.up.pt

J Dent Res X(X):XX-XX, XXXX

\section{ABSTRACT}

In spite of recent developments, data regarding the genes responsible for the less severe forms of hypodontia are still scarce and controversial. This study addressed the hypothesis that agenesis of maxillary lateral incisors (MLIA) is a distinct type of hypodontia, by evaluating its familial aggregation and the occurrence of other types of ageneses or microdontia in probands' relatives. Sixty-two probands with MLIA were identified, and information was collected on 142 first-degree relatives. Relative risk (RR) was calculated and compared by re-assessment of data previously published for the Swedish, Utah, and Israeli populations, for the same trait. A RR of 15 was obtained in the Portuguese, 16 in the Swedish, 12 in Utah, and 5 in the Israeli population. Our results support a significant familial aggregation of MLIA, show that MLIA almost never segregates with other forms of agenesis, and suggest that microdontia of maxillary lateral incisors is part of the same phenotype.

KEY WORDS: hypodontia, microdontia, maxillary lateral incisors, relative risk, familial aggregation.

\section{DOI: $10.1177 / 0022034510364486$}

Received April 23, 2008; Last revision January 7, 2010; Accepted January 21, 2010

A supplemental appendix to this article is published electronically only at http://jdr.sagepub.com/supplemental.

\title{
Familial Aggregation of Maxillary Lateral Incisor Agenesis
}

\section{INTRODUCTION}

A genesis of maxillary lateral incisors (MLIA) and mandibular second premolars is the most frequent form of hypodontia, its frequency varying across populations (Grahnén, 1956; Horowitz, 1966; Alvesalo and Portin, 1969; Muller et al., 1970; Thilander and Myrberg, 1973; Magnusson, 1977; Rolling, 1980; Aasheim and Øgaard, 1993; Johannsdottir et al., 1997; Tavajohi-Kermani et al., 2002; Polder et al., 2004). Values between 0.8 and $4.25 \%$ have been found for MLIA in permanent teeth. In the Portuguese population, MLIA prevalence was estimated at 1.3\% (Pinho et al., 2005).

In spite of recent progress, the etiopathogenesis of hypodontia is largely unknown, although there is strong support for the hypothesis of a genetic etiology. There is evidence showing that congenital tooth absence can be the result of environmental or hereditary causes, or their interaction (Vastardis, 2000). Grahnén's study (1956) in the Swedish population confirmed the hypothesis of a genetic component for hypodontia and attempted to clarify its modes of inheritance. Familial segregation studies suggested that hypodontia showed an autosomal-dominant inheritance in some families, with incomplete penetrance and variable expressivity (Grahnén, 1956; Svinhufvud et al., 1988; Vastardis et al., 1996; Arte et al., 2001); however, modes of transmission linked to the X-chromosome and of polygenic or multifactorial type have also been proposed (Chosack et al., 1975). Grahnén (1956) and Alvesalo and Portin (1969), among others, strongly suggested that peg-shaped incisors are a variable expression of the gene responsible for MLIA, an argument also presented by Arte et al. (2001). Woolf's study (1971) focused only on MLIA.

The identification of phenotypes of tooth absence and hypoplasia in mouse lines null-zygous for different genes, together with the identification of mutations causing hypodontia in a relatively small number of human families (Vastardis et al., 1996; Stockon et al., 2000; van den Boogaard et al., 2000; Nieminen et al., 2001; Frazier-Bowers et al., 2002; Mostowska et al., 2006; Kapadia et al., 2006; Tao et al., 2006; Tarpey et al., 2007), confirmed the relevance of genetic determination of tooth agenesis. However, the role of genes in sporadic and less severe forms of hypodontia has not yet been clarified. Additionally, there is evidence for an extensive clinical and genetic heterogeneity within the "hypodontia" phenotype. Further definition of clinical and genetic subtypes within hypodontia is thus required, and familial aggregation studies are needed to establish a measure of the genetic contribution to different subtypes of congenital tooth absence, as well as their modes of inheritance-a first step toward the identification of causative genes. 
Table 1. Frequency of Agenesis of Maxillary Lateral Incisors (MLIA) in Relatives of Probands Compared with General Population

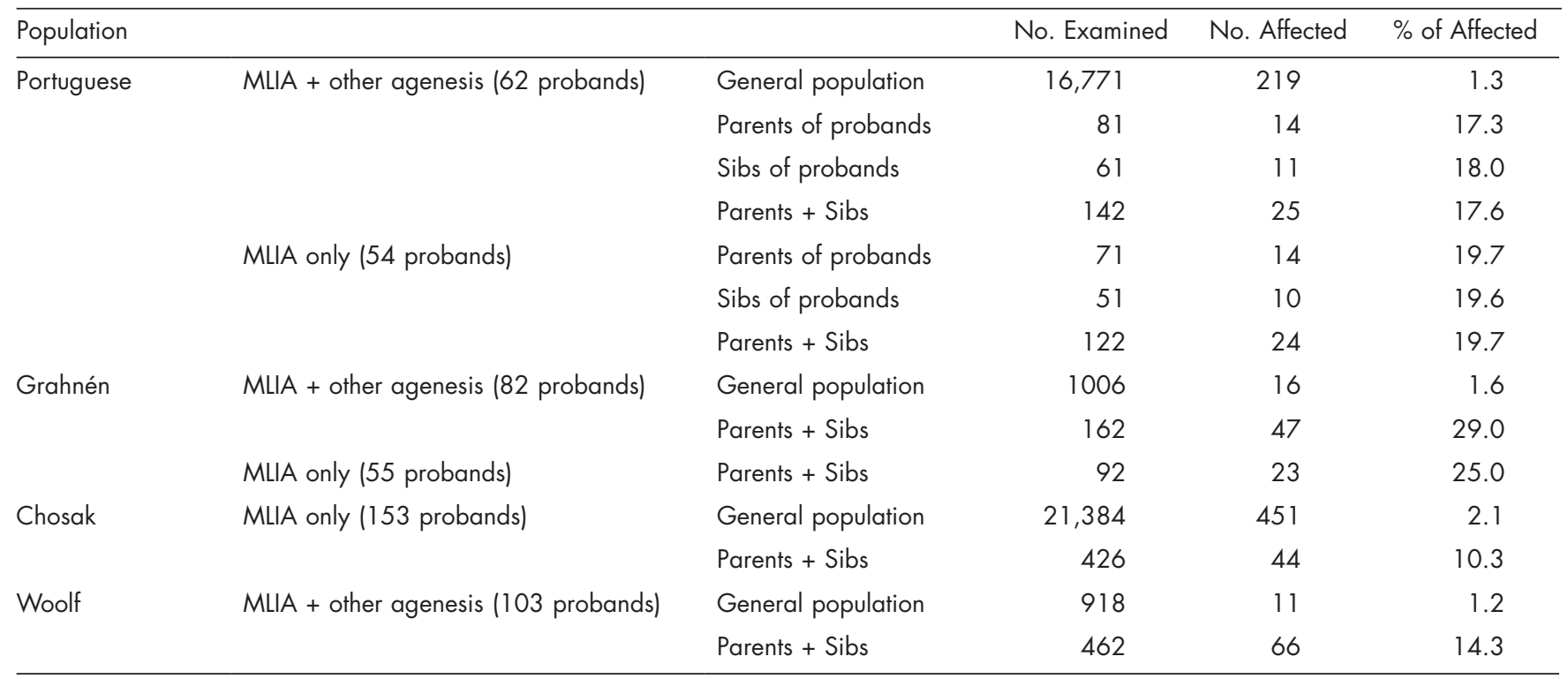

In a previous population-based study of hypodontia in Portugal (Pinho et al., 2005), we found that $87 \%$ of MLIA subjects had no other form of agenesis. In accordance with Woolf (1971), we hypothesized that MLIA is a separate genetic entity within the hypodontia phenotype. In addition, $57.1 \%$ of the 121 subjects with unilateral MLIA also showed microdontia of the contralateral maxillary lateral incisor.

Our strategy was (1) to investigate the degree of familial aggregation for MLIA, (2) to assess which other forms of agenesis segregate in these families, and (3) to test the hypothesis that microdontia of maxillary lateral incisors is a milder form of the MLIA phenotype. We obtained novel data regarding MLIA in the Portuguese population, and re-assessed data published by Grahnén (1956) for the Swedish population, by Woolf (1971) for the Utah population, and by Chosack et al. (1975) from Israel. For the first time, relative risk was estimated in MLIA families. Estimates derived from four populations are presented and discussed.

\section{PARTICIPANTS \& METHODS}

\section{Subjects}

\section{Portuguese Data}

Our sample consisted of 62 selected probands, observed at a University Medical Dentistry School Clinic, showing MLIA, whether right unilateral, left unilateral, or both (54 isolated and eight together with other forms of agenesis). Pedigrees of these 62 families were then built. First-degree relatives of these probands (with and without agenesis) were enrolled in the study, and clinical and radiographic observations were made. In all cases, diagnosis was performed by direct observation of the presence and the morphology of the maxillary lateral incisors in the dental arch and, in cases of apparent absence, by radiography, dental history, or information given by the family dentist. Additionally, any form of agenesis or microdontia was recorded. As suggested by Proffit (2007), maxillary lateral incisors were considered microdontic when their mesiodistal dimensions were smaller than those of the lower lateral incisors.

The study was approved by the Ethics Committee of the Medical Dentistry School. Patient or parental written informed consent was obtained in all cases.

\section{Data from Sweden, Utah, and Israel}

We re-assessed the data published by Grahnén (1956), focusing only on MLIA. Of those 171 families, 82 had probands with MLIA, and we then analyzed the occurrence of the same phenotype in their parents and sibs (Table 1). Woolf's study (1971) consisted of 103 probands with MLIA and 187 control families from Utah and their parents and sibs (Table 1). Chosack et al. (1975) studied families of 153 probands with MLIA (Table 1).

\section{Methods}

\section{Measuring Familial Aggregation}

Relative risk (RR) represents the ratio between the frequency of the disease in relatives of probands and its prevalence in the population (Cantor and Rotter, 1992) and was used as a measure of familial aggregation. We estimated RR for probands' relatives also to be affected with MLIA when compared with the general population, using a prevalence rate of $1.3 \%$ for the Portuguese (Pinho et al., 2005), 1.6\% for the Swedish (Grahnén, 1956), $1.2 \%$ for Utah (Woolf, 1971), and 2.1\% for Israel (Chosack et al., 1975) (Table 1).

In comparisons between our data and data from Sweden, Utah, or Israel, only RR for parents and sibs (altogether) were considered (Table 2).

Probands and relatives were classified as affected when they showed only MLIA, and as unaffected when having no dental agenesis; relatives with MLIA together with other forms of hypodontia were excluded from the RR calculations (Table 2).

Since Woolf's study did not provide data on MLIA only, and for the purpose of comparisons of our data with those data, we 
Table 2. Relative Risks (for parents and sibs) in Our Study and Other Studies

\begin{tabular}{lcc}
\hline $\begin{array}{l}\text { Probands and } \\
\text { Relatives Affected }\end{array}$ & RR $(95 \% \mathrm{CI})^{\mathrm{a}}$ & RRR $^{\mathrm{b}}$ \\
\hline $\begin{array}{l}\text { MLIA only } \\
\text { Our data }\end{array}$ & $14.68(9.94-21.68)$ & - \\
Grahnén & $15.72(8.62-28.68)$ & $0.93(0.45-1.90)$ \\
Chosack et al. & $4.90(9.94-21.68)$ & $3.00(1.84-4.88)$ \\
MLIA + other agenesis & & - \\
Our data & $13.58(9.29-19.84)$ & $-14(0.55-2.37)$ \\
Woolf & $11.92(6.4-22.4)$ & 1.14 \\
\hline
\end{tabular}

(a) Using the prevalence of maxillary lateral incisor agenesis (MLIA) in the four studies: our data, 1.3\% (219/16771), Grahnén, $1.6 \%$ (16/1006), Chosack et al., 2.2\% (451/21384), Woolf, $1.2 \%(11 / 918)$.

(b) RRR: Ratio of relative risks (Cl), between our study and others.

performed a second analysis in which probands and relatives were classified as affected when showing MLIA (whether isolated or together with other agenesis), and as unaffected when having no MLIA (Table 2).

\section{Further Analysis of Portuguese Data}

To test the hypothesis that MLIA is a separate clinical and genetic entity, we analyzed the type of agenesis and the occurrence of microdontia in parents and sibs of probands with MLIA only or with MLIA plus other ageneses (Table 3). We also assessed if, in parents and sibs, MLIA was bilateral, unilateral with microdontia of the contralateral tooth, or unilateral.

We further analyzed 54 Portuguese families whose proband had MLIA only. First, we investigated whether the frequency of affected first-degree relatives differed according to severity in the proband, i.e., whether MLIA in the proband was bilateral, unilateral with microdontia of the contralateral tooth, or unilateral. We then looked for patterns of transmission of MLIA (and microdontia) in those families.

\section{Statistical Analysis}

We assessed comparisons between and among categorical variables using chi-square tests. We made comparisons between and among RR using the ratio of relative risks (RRR) (Altman and Bland, 2003). Values of RR are given with $95 \%$ confidence intervals. A 5\% significance level was used in all analyses. Statistical analyses were performed with SPSS (version 14.0 for Windows).

\section{RESULTS}

\section{New and Re-assessed Evidence for Familial Aggregation of MLIA}

\section{Portuguese Data}

Among 122 first-degree relatives of probands with MLIA only, $24(19.7 \%$ ) also had MLIA (Table 1); therefore, the risk for a
Table 3. Phenotype in Relatives of Probands with Maxillary Lateral Incisor Agenesis (MLIA) only (1) or MLIA with Other Forms of Agenesis (2)

\begin{tabular}{lrrrrr}
\hline & \multicolumn{2}{c}{ Parents } & & \multicolumn{2}{c}{ Sibs } \\
\cline { 2 - 3 } \cline { 6 - 7 } Phenotype in Relatives & $11)$ & $(2)$ & & $(1)$ & $(2)$ \\
\hline No agenesis & 54 & 5 & & 35 & 8 \\
MLIA only & 14 & 0 & 9 & 0 \\
Bilateral & 11 & 0 & & 7 & 0 \\
Unilateral + microdontia & 2 & 0 & & 2 & 0 \\
Unilateral & 1 & 0 & & 0 & 0 \\
Microdontia of lateral incisors only & 3 & 4 & & 6 & 0 \\
MLIA + other agenesis & 0 & 0 & & 1 & 1 \\
Other agenesis without MLIA & 0 & 0 & & 0 & 0 \\
Other agenesis + microdontia & 0 & 1 & & 0 & 1 \\
Total observed & 71 & 10 & 51 & 10 \\
\hline
\end{tabular}

relative of a proband with MLIA to have the same kind of agenesis was about 15 times greater (Table 2) than for an individual from the general population. For the purpose of comparison with Woolf's data, a second estimate of 14 for RR was obtained (Table 2), including as affected both probands (62) and relatives (142) with MLIA together with other forms of agenesis.

\section{Comparing Portuguese and Swedish Data}

Grahnén's data consisted of 92 parents or sibs of 55 probands with MLIA (23 affected; Table 1), leading to a RR of 15.72 (Table 2). RRR showed no significant differences between this data set and ours (Table 2).

\section{Comparing Data from Portugal and Utah}

Woolf's data consisted of 462 parents or sibs of 103 MLIA cases (66 affected; Table 1). RR for first-degree relatives of MLIA probands was 11.9 (Table 2). RRR showed no significant differences between this data set and ours (Table 2). Since data from Utah were not stratified according to the pure MLIA phenotype, it was not possible to establish this other comparison.

\section{Comparing Portuguese and Israeli Data}

Chosack's data consisted of 426 parents or sibs of 153 MLIA probands, of whom 44 were also affected (Table 1), leading to a RR of 4.9 (Table 2). In spite of being lower than RR derived from the other three populations, the RR is still considerably high.

\section{Further Analysis of Portuguese Data}

\section{MLIA is a Distinct Clinical and Genetic Entity}

All forms of agenesis or microdontia found in relatives of both groups of probands are described (Table 3). The most frequent phenotype by far was MLIA only, followed by microdontia of contralateral incisors. Other types of ageneses were found in only four out of 142 first-degree relatives (Table 3) and were associated either with MLIA (two cases) or with microdontia (two cases) (Table 3). No other form of agenesis was found on its own. 
A

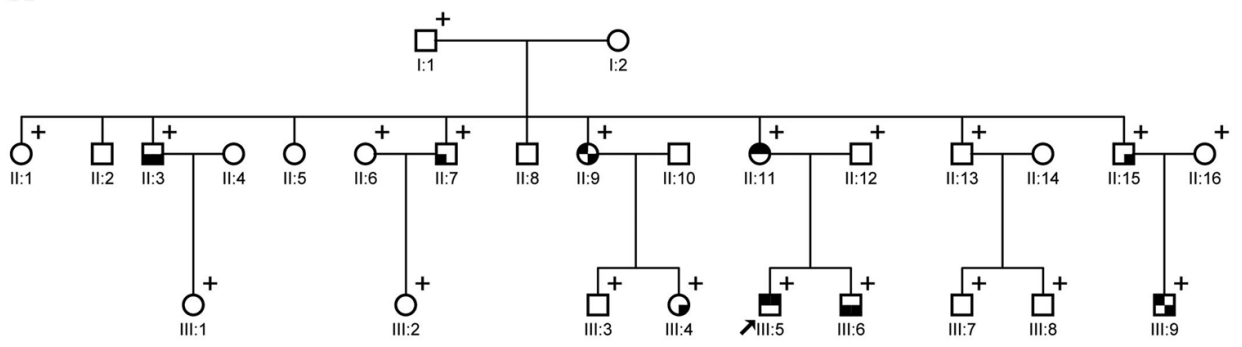

B

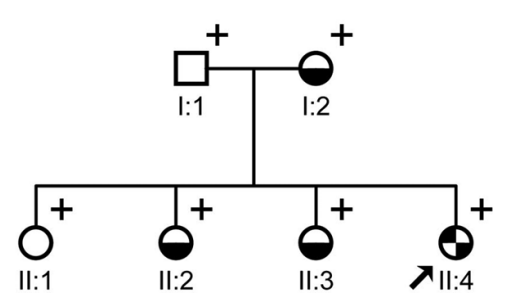

$\mathrm{C}$

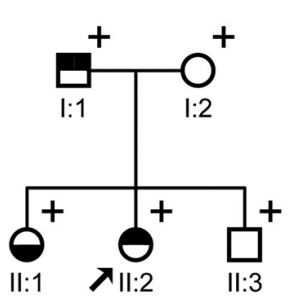

Figure. Pedigrees of 3 Portuguese families (A,B,C). Legend: 1 . Black-filled symbols: $(\boldsymbol{\Xi}, \boldsymbol{\Theta})$ Upper half - bilateral agenesis of maxillary lateral incisors; $(\square, 0)$ Upper left quadrant - unilateral agenesis of lateral incisor (12); $(\boldsymbol{\square}, \boldsymbol{\Theta})$ Upper right quadrant - unilateral agenesis of lateral incisor $(22) ;(\boldsymbol{\bullet}, \boldsymbol{\bullet})$ Lower half - bilateral microdontia of maxillary lateral incisors; $(\boldsymbol{\nabla}, \boldsymbol{\bullet})$ Lower left quadrant - unilateral microdontia of lateral incisor (12); $(\mathbf{Q}, \boldsymbol{\odot})$ Lower right quadrant - unilateral microdontia of lateral incisor (22); (勿 Vertical solid bar - affected with agenesis (hearsay). 2. (त) Arrow: probands. 3. (+) Plus sign: individuals clinically examined.

\section{Severity in Proband Correlates with Frequency of Affected Relatives}

Frequency of affected relatives with MLIA was $22.5 \%$ when the proband had bilateral MLIA, 18.2\% when the proband had both unilateral MLIA and microdontia of the contralateral tooth, and $12.5 \%$ when the proband had only unilateral MLIA (not shown), indicating a gradient of affected relatives according to severity in the proband.

Our probands showed bilateral MLIA in $52 \%$ of the cases, and unilateral with microdontia of the contralateral tooth in $34 \%$; only $14 \%$ of probands displayed unilateral MLIA alone. In relatives, the same gradient of frequencies could be observed (Table 3), adding evidence that microdontia forms an intermediate phenotype.

\section{Mode of Transmission of MLIA}

Our analysis of 54 families whose probands had pure MLIA revealed that, in 19, vertical transmission was observed, which was compatible with autosomal-dominant transmission (in three of these, there was evidence of incomplete penetrance). In 18 other families, although transmission was also compatible with $\mathrm{AD}$ inheritance with incomplete penetrance, autosomal-recessive inheritance could not be ruled out, mostly due to small family size or lack of information. Pedigrees of these 37 families are included in the Appendix. The remaining 17 families were not informative (neither parent could be observed).

We observed similar frequencies of affected parents (19.7\%) and affected sibs (19.6\%) of MLIA probands (Table 1), which is counter to the hypothesis of recessive inheritance. Since father-son transmission was also observed in several pedigrees, analysis of our data suggests that autosomal-dominance with incomplete penetrance plays an important (although not exclusive) role in MLIA transmission.

When we included microdontia in relatives as part of the same phenotype (not shown), the frequencies of affected parents and sibs of MLIA probands were 24 and $32 \%$, respectively, not significantly different at this sample size.

Three families where cases of MLIA and microdontia segregated in the same pedigree, often occurring in the same individual, are depicted in the Fig.

\section{DISCUSSION}

In this work, we studied familial aggregation of MLIA in an attempt to investigate the hypothesis of a genetic basis for this subtype of hypodontia. As in previous studies, we found strong familial aggregation of MLIA, as derived from a higher frequency of affected individuals among affected probands' relatives than in the general population.

Results from Portuguese data showed that risk for a firstdegree relative of an individual with MLIA to have the same kind of agenesis was about 15 times higher than that of the general population. Comparisons between our estimates and RR derived from Grahnén and Woolf's series showed that, in all three populations, RR were not significantly different from each other. Although the estimate from Chosack's data was lower than the other three, RR was consistently high in the four populations, and their magnitude was too high to be due to environmental factors only (Khoury et al., 1988). Analysis of our data also showed that the presence of other forms of agenesis in relatives of MLIA probands is residual and always associated with MLIA or with microdontia, which is also consistent with previously published results (Pinho et al., 2005), where $87 \%$ of patients with MLIA had no other form of agenesis. In our opinion, these results show that it is worth concentrating on MLIA as a separate clinical entity.

Moreover, phenotype definition should include microdontia of lateral incisors, which should be considered a milder form of the MLIA phenotype, as suggested previously (Alvesalo and Portin, 1969) in peg-shaped incisors. In our data, bilateral MLIA or MLIA, together with microdontia, was more frequent than unilateral MLIA (in both probands and relatives), a result in accordance with the meta-analysis performed by Polder et al. (2004). When the epidemiological data were re-assessed (Pinho et al., 2005), 78\% of individuals displayed a bilateral phenotype (bilateral agenesis or unilateral agenesis with contralateral microdontia), which is in accordance with the hypothesis of a developmental disturbance. 
In spite of recent developments in the genetics of hypodontia, data regarding the genes responsible for MLIA are still scarce and controversial. The search for genes associated with anterior hypodontia has been largely unsuccessful so far, and several of the known hypodontia candidate genes, including MSX1 (Nieminen et al., 1995; Vastardis et al., 1996; Scarel et al., 2000; Vastardis, 2000; Lidral and Reising, 2002) and PAX9 (Stockton et al., 2000; Nieminen et al., 2001; FrazierBowers et al., 2002; Mostowska et al., 2006; Kapadia et al., 2006), seem to have an important role mostly in posterior tooth odontogenesis. A plausible hypothesis is that the various hypodontia patterns are the result of different types of mutations in different genes, as suggested by Vastardis (2000), possibly also involving gene-gene and gene-environment interactions.

It is thus probable that different genes are involved in different phenotypes. The consistently high RR for MLIA across four different populations also indicates that it is worth looking for genes specifically within this phenotype.

Analysis of our data suggests that the pattern of segregation of MLIA (including microdontia of maxillary lateral incisors) is compatible with an autosomal-dominant trait with incomplete penetrance (although in some families recessive inheritance could not be excluded); further studies are needed that will allow us to proceed to the mapping and identification of genes that play a role in the determination of this phenotypic trait.

\section{ACKNOWLEDGMENTS}

The individuals who took part in this study are acknowledged. Carolina Lemos was the recipient of a PhD scholarship (FCT SFRH/BD/17761/2004) and Teresa Pinho of a PhD scholarship from Instituto Superior de Ciências da Saúde Norte/CESPU. The other authors received no funding from any institution, department, or sponsor, other than salaries from the institutions with which they are affiliated.

\section{REFERENCES}

Aasheim B, Øgaard B (1993). Hypodontia in 9-year-old Norwegians related to need of orthodontic treatment. Scand J Dent Res 101:257-260.

Altman DG, Bland JM (2003). Interaction revisited: the difference between two estimates. BMJ 326:219.

Alvesalo L, Portin P (1969). The inheritance pattern of missing, peg-shaped and strongly mesiodistally reduced upper lateral incisors. Acta Odontol Scand 27:563-575.

Arte S, Nieminen P, Apajalahti S, Haavikko K, Thesleff I, Pirinen S (2001). Characteristics of incisor-premolar hypodontia in families. $J$ Dent Res 80:1445-1450.

Cantor RM, Rotter JI (1992). Analysis of genetic data: methods and interpretation. In: The genetic basis of common diseases. King RA, Rotter JI, Motulsky AG, editors. New York, NY: Oxford University Press, pp. 49-70.

Chosack A, Eidelman E, Cohen T (1975). Hypodontia: a polygenic trait-a family study among Israeli Jews. J Dent Res 54:16-19.

Frazier-Bowers SA, Guo DC, Cavender A, Xue L, Evans B, King T, et al. (2002). A novel mutation in human PAX9 causes molar oligodontia. $J$ Dent Res 81:129-133.

Grahnén H (1956). Hypodontia in the permanent dentition. A clinical and genetic investigation. Odont Rev 7(Suppl 3):1-100.
Horowitz JM (1966). Aplasia and malocclusion: a survey and appraisal. Am J Orthod 52:440-453.

Johannsdottir B, Wisth PJ, Magnusson TE (1997). Prevalence of malocclusion in 6-year-old Icelandic children. Acta Odontol Scand 55:398-402.

Kapadia H, Frazier-Bowers S, Ogawa T, D’Souza RN (2006). Molecular characterization of a novel PAX9 missense mutation causing posterior tooth agenesis. Eur J Hum Genet 14:403-409.

Khoury MJ, Beaty TH, Liang KY (1988). Can familial aggregation of disease be explained by familial aggregation of environmental risk factors? Am J Epidemiol 127:674-683.

Lidral AC, Reising BC (2002). The role of MSX1 in human tooth agenesis $J$ Dent Res 81:274-278.

Magnusson TE (1977). Prevalence of hypodontia and malformations of permanent teeth in Iceland. Community Dent Oral Epidemiol 5:173-178.

Mostowska A, Biedziak B, Jagodzinski PP (2006). Axis inhibition protein 2 (AXIN2) polymorphisms may be a risk factor for selective tooth agenesis. J Hum Genet 51:262-266.

Muller TP, Hill IN, Peterson AC, Blayney JR (1970). A survey of congenitally missing permanent teeth. J Am Dent Assoc 81:101-107.

Nieminen P, Arte S, Pirinen S, Peltonen L, Thesleff I (1995). Gene defect in hypodontia; exclusion of MSX1 and MSX2 as candidate genes. Hum Genet 96:305-308

Nieminen P, Arte S, Tanner D, Paulin L, Alaluusua S, Thesleff I, et al. (2001). Identification of a nonsense mutation in the PAX9 gene in molar oligodontia. Eur J Hum Genet 9:743-746.

Pinho T, Tavares P, Maciel P, Pollmann C (2005). Developmental absence of maxillary lateral incisors in the Portuguese population. Eur J Orthod 27:443-449.

Polder BJ, Van'tHof MA, Van der Linden FP, Kuijpers-Jagtman AM (2004). A meta analysis of the prevalence of dental agenesis of permanent teeth. Community Dent Oral Epidemiol 32:217-226.

Proffit WR, Fields HW, Sarver DM (2007). Contemporary orthodontics. 4th ed. St. Louis: C.V. Mosby \& Co.

Rolling S (1980). Hypodontia of permanent teeth in Danish schoolchildren. Scand J Dent Res 88:365-369.

Scarel RM, Trevilatto PC, Camargo LE, Line SR (2000). Absence of mutations in the homeodomain of the MSX1 gene in patients with hypodontia. Am J Med Genet 92:346-349.

Stockton DW, Das P, Goldenberg M, D’Souza RN, Patel PI (2000). Mutation of PAX9 is associated with oligodontia. Nat Genet 24: 18-19.

Svinhufvud E, Myllarniemi S, Norio R (1988). Dominant inheritance of tooth malpositions and their association to hypodontia. Clin Genet 34:373-381.

Tao R, Jin B, Guo SZ, Qing W, Feng GY, Brooks DG, et al. (2006). A novel missense mutation of the EDA gene in a Mongolian family with congenital hypodontia. J Hum Genet 51:498-502.

Tarpey P, Pemberton TJ, Stockton DW, Das P, Ninis V, Edkins S, et al. (2007). A novel Gln358Glu mutation in ectodysplasin A associated with X-linked dominant incisor hypodontia. Am J Med Genet 143:390-394.

Tavajohi-Kermani H, Kapur R, Sciote JJ (2002). Tooth agenesis and craniofacial morphology in an orthodontic population. Am J Orthod Dentofacial Orthop 122:39-47.

Thilander B, Myrberg N (1973). The prevalence of malocclusion in Swedish schoolchildren. Scand J Dent Res 81:12-21.

van den Boogaard MJ, Dorland M, Beemer FA, Van Amstel HK (2000). MSX1 mutation is associated with orofacial clefting and tooth agenesis in humans. Nat Genet 24:342-343.

Vastardis H (2000). The genetics of human tooth agenesis: new discoveries for understanding dental anomalies. Am J Orthod Dentofacial Orthop 117:650-656.

Vastardis H, Karimbux N, Guthua SW, Seidman JG, Seidman CE (1996). A human MSX1 homeodomain missense mutation causes selective tooth agenesis. Nat Genet 13:417-421.

Woolf CM (1971). Missing maxillary lateral incisors: a genetic study. Am J Hum Genet 23:289-296. 